\title{
Associations between activation-induced cytidine deaminase/apolipoprotein B mRNA editing enzyme, catalytic polypeptide-like cytidine deaminase expression, hepatitis B virus (HBV) replication and $\mathrm{HBV}$-associated liver disease (Review)
}

\author{
XIUTING HE ${ }^{1}$, JIE LI $^{1}$, JING WU ${ }^{1}$, MANLI ZHANG ${ }^{2}$ and PUJUN GAO ${ }^{3}$ \\ ${ }^{1}$ Department of Geriatrics, The First Hospital of Jilin University; ${ }^{2}$ Department of Gastroenterology, \\ The Second Branch of The First Hospital of Jilin University; ${ }^{3}$ Department of Hepatology, \\ The First Hospital of Jilin University, Changchun, Jilin 130021, P.R. China
}

Received November 20, 2014; Accepted August 25, 2015

DOI: $10.3892 / \mathrm{mmr} .2015 .4312$

\begin{abstract}
The hepatitis B virus (HBV) infection is a major risk factor in the development of chronic hepatitis $(\mathrm{CH})$ and hepatocellular carcinoma (HCC). The activation-induced cytidine deaminase (AID)/apolipoprotein B mRNA editing enzyme, catalytic polypeptide-like (APOBEC) family of cytidine deaminases is significant in innate immunity, as it restricts numerous viruses, including $\mathrm{HBV}$, through hypermutation-dependent and -independent mechanisms. It is important to induce covalently closed circular (ccc)DNA degradation by interferon- $\alpha$ without causing side effects in the infected host cell. Furthermore, organisms possess multiple mechanisms to regulate the expression of AID/APOBECs, control their enzymatic activity and restrict their access to DNA or RNA substrates. Therefore, the AID/APOBECs present promising targets for preventing and treating viral infections. In addition, gene polymorphisms of the AID/APOBEC family may alter host susceptibility to $\mathrm{HBV}$ acquisition and $\mathrm{CH}$ disease progression. Through G-to-A
\end{abstract}

Correspondence to: Professor Pujun Gao, Department of Hepatology, The First Hospital of Jilin University, 71 Xinmin Street, Changchun, Jilin 130021, P.R. China

E-mail: pujun-gao@163.com

Abbreviations: AID, activation-induced cytidine deaminase; APOBEC, apolipoprotein B mRNA editing enzyme, catalytic polypeptide-like; HCC, hepatocellular carcinoma; cccDNA, covalently closed circular DNA; ApoB48, apolipoprotein B; IFN- $\alpha$, interferon- $\alpha$; $\mathrm{PHH}$, primary human hepatocytes; ssDNA, single stranded DNA; SHM, somatic hypermutation; HMM, high molecular mass; rcDNA, relaxed circular DNA; pgRNA, pregenomic RNA; UNG, uracil DNA glycosylases; RT, reverse transcriptase; FRET, fluorescence resonance energy transfer; $\mathrm{CH}$, chronic hepatitis

Key words: hepatitis B virus, activation-induced cytidine deaminase, apolipoprotein B mRNA editing enzyme, catalytic polypeptide-like, polymorphism, hepatocellular carcinoma hypermutation, AID/APOBECs also edit HBV DNA and facilitate the mutation of HBV DNA, which may assist the virus to evolve and potentially escape from the immune responses. The AID/APOBEC family and their associated editing patterns may also exert oncogenic activity. Understanding the effects of cytidine deaminases in $\mathrm{CH}$ virus-induced hepatocarcinogenesis may aid with developing efficient prophylactic and therapeutic strategies against HCC.

\section{Contents}

1. Introduction

2. AID/APOBEC family of deaminases

3. Specific regulation of editing by AID/APOBECs

4. Role of AID/APOBECs in HBV-associated disease progression

5. Inhibition of HBV by AID/APOBEC proteins

6. APOBEC polymorphisms in HBV infections

7. Emerging role of the AID/APOBEC family in the development of cancer

8. Conclusion

\section{Introduction}

The hepatitis B virus (HBV) infection is a prevalent type of infectious disease that is causing a global concern for public health (1). Although there has been considerable improvement in understanding the molecular virology and pathogenesis of the HBV infection over the past decade and effective therapeutic measures have been developed for its treatment, there are currently 240 million individuals globally who are chronic HBV carriers, and $\sim 620,000$ succumb per year due to late sequelae of liver cirrhosis or hepatocellular carcinoma (HCC) (1). The treatment of chronic hepatitis $(\mathrm{CH}) \mathrm{B}$ is currently limited; predominantly consisting of interferons (IFNs) and nucleoside analogs (NUCs) (2). NUCs are efficient antiviral agents, however, NUCs only control rather 
than cure HBV infections due to persistent viral covalently closed circular (ccc)DNA. Therefore, a long-term treatment is required, which is expensive and may lead to concomitant resistance (2). IFN therapy is associated with side effects, and treatment with this cytokine can result in viral clearance in a small proportion of patients (3). Thus, it is important to continue conducting research in order to identify therapeutic targets to stimulate the development of novel antiviral agents and immunotherapies.

The activation-induced cytidine deaminase (AID)/apolipoprotein $B$ mRNA editing enzyme, catalytic polypeptide-like (APOBEC) family, which was first described for inhibition of human immunodeficiency virus type 1 (HIV-1), is important in the innate immune system, as it defends against viruses, including HBV through hypermutation-dependent and -independent mechanisms. Nine of 11 APOBEC 3 family members have been identified to exert varying levels of activity against HBV under experimental conditions (Table I). APOBEC-3A and APOBEC-3B are essential for cccDNA degradation by IFN- $\alpha$ or the lymphotoxin- $\beta$ receptor-agonist without damaging the infected host cells (4). Thus, targeting the formation and subsequent processing of viral cccDNA may be more rational approaches.

The aim of the present study was to review the rapidly accumulating evidence for the involvement of AID/APOBEC cytidine deaminase expression and HBV replication, and to summarize the current knowledge surrounding the role of editing in HBV-associated liver disease as a consequence of its actions in host cells.

\section{AID/APOBEC family of deaminases}

AID/APOBEC family members. All members of the AID/APOBEC family possess one or two catalytic domains that deaminate cytidine in RNA and DNA. The deaminases mediate the hydrolytic removal of an amino group at the $\mathrm{C} 4$ position of a cytidine $(\mathrm{C})$ or deoxycytidine $(\mathrm{dC})$ generating a uridine $(\mathrm{U})$ or deoxyuridine $(\mathrm{dU})$, respectively $(5)$. The presence of the enzyme in cells producing RNA virus results in C-to-U conversion of minus strand reverse transcripts and G-to-A in plus strand DNA. The binding to the target DNA creates a U-G mismatch, which generates a C-to-T transition in minus strand DNA and a G-to-A transition in plus strand DNA during general DNA replication without repair pathways (Fig. 1) (6). In humans, the family comprises 11 members with distinct functions, including AID, APOBEC1 (A1), APOBEC2 (A2), APOBEC4 (A4) and APOBEC3 (A3) subgroups. The A3 group consists of seven proteins: A3A, A3B, A3C, A3DE, A3F, A3G and $\mathrm{A} 3 \mathrm{H}(7-10)$. The seven $\mathrm{A} 3$ genes are arranged in a tandem gene cluster on chromosome 22 in humans (11). The presence of the AID/APOBEC family is restricted to vertebrates. AID and $\mathrm{A} 2$ are likely to be the ancestral members, while $\mathrm{A} 1$ and $\mathrm{A} 3$ are later evolutionary arrivals (12), A3s are restricted to placental mammals, and their gene copy number is species-specific. For example, mice only possess a single A3 gene, pigs have two, sheep and cattle have three, cats have four, horses have six and primates have at least seven A3 genes (13). The rapid expansion of the A3 locus in humans indicates an important role in the host genome defense against exogenous viruses and endogenous retroelements (12-14). The role of the AID/APOBEC family in the inhibition of viral infection was initially described for HIV-1. Various studies have shown that the genome of hepadnaviruses is hyperedited by cytidine deaminases (15-21). Recent reports demonstrated that HBV DNA replication is restricted by A1, AID, A3A, A3B, A3C, A3G, A3F, but not A3DE (4,15,17,22-26), specifically via the degradation of HBV cccDNA (4), which was investigated in an experimental setting through deaminase-independent and -dependent mechanisms $(27,28)$.

AID/APOBEC family gene expression. A1 is primarily expressed in the gastrointestinal compartment and catalyzes the expression of a truncated form of apolipoprotein (Apo) B (ApoB48) with the distinct biological function of ApoB100 (10). AID is expressed in germinal center B cells and randomly edits $\mathrm{dC}$ residues to $\mathrm{dU}$ in the variable region of immunoglobulin gene loci, which is essential for the process of antibody diversification (29,30). As expected, AID and A1 were not detected in the HCC cell lines and liver tissue $(20,25)$. A2 is widely expressed in muscle; predominantly in cardiac and skeletal muscle, thus, is exclusively associated with the development of cardiac and skeletal muscle, as well as early embryogenesis (9,31-33). A4 was discovered by a computational homology search and was found to be expressed in the testicles, although its function remains undetermined (8). A3 (particularly A3G and $\mathrm{A} 3 \mathrm{~F}$ ) is widely expressed in human tissues, where the mRNA levels broadly correlate with the lymphoid cell content (with the exception of gonadal tissues) (34). In the healthy human liver, low to moderate APOBEC expression levels have been observed $(11,20,26,35,36)$, with $\mathrm{A} 3 \mathrm{G}$ expression levels identified to be the highest, followed by $\mathrm{A} 3 \mathrm{C}$ and $\mathrm{A} 3 \mathrm{H}$ expression (18). Positive transcription and expression has been identified for $\mathrm{A} 3 \mathrm{G}, \mathrm{A} 3 \mathrm{C}$ and $\mathrm{A} 3 \mathrm{H}$ in $\mathrm{HepG} 2$ cells, although not for A3B and A3F. Amplification experiments with A2- and A3A-specific primers resulted in particularly faint signals, and A1- and A3DE-specific sequences were not detected (18).

Onset of liver disease results in changes to the levels of these deaminases. For example, in hepatitis/cirrhotic samples, five of seven $\mathrm{A} 3$ genes were significantly upregulated in the following order: $\mathrm{HCV} \pm \mathrm{HBV}>\mathrm{HBV}>$ alcoholic cirrhosis. A3C and A3D were upregulated for all groups, while IFN inducible A3G was overexpressed in virus-associated cirrhotic patients, and AID was present in 50\% of the HBV/HCV samples (21). The expression levels of A1, A2, and A4 were not identified to be significantly different between cirrhotic liver and normal tissue samples (21). Furthermore, the A3B cytidine deaminase was widely upregulated in HCC tumor tissue samples (37).

Upregulation by IFNs and other cytokines. The expression of APOBEC genes is induced by IFNs, as well as other cytokines. IFN- $\alpha$ has been observed to trigger the expression of A3 in numerous reports. For example, treatment with IFN- $\alpha$ in primary human hepatocytes (PHHs) and $\mathrm{HCC}$ cell lines resulted in induction of A3-associated genes, particularly A3G; however, no changes were triggered in the expression of A1, A2 or AID $(25,26,36)$. In addition, A3A was demonstrated to be significantly expressed in peripheral blood mononuclear cells, HBV-infected differentiated HepaRG cells and PHHs that were treated with IFN- $\alpha(4,36,38)$. IFN- $\alpha$ enhances A3 expression levels in human macrophages (39), phagocytes (38) and peripheral plasmacytoid dendritic cells (40). This indicates that A3 
Table I. Reported hyperediting and restriction activity of AID/APOBECs against HBV DNA.

\begin{tabular}{|c|c|c|c|c|}
\hline $\begin{array}{l}\text { Cytidine } \\
\text { deaminases }\end{array}$ & $\begin{array}{l}\text { Hyperediting } \\
\text { activity }\end{array}$ & $\begin{array}{l}\text { Dinucleotide } \\
\text { preference }\end{array}$ & $\begin{array}{l}\text { Restriction activity } \\
\text { against HBV DNA }\end{array}$ & Reference \\
\hline AID & $\begin{array}{l}\text { Deaminates each viral RNA and } \\
\text { HBV minus-strand DNA }\end{array}$ & $\mathrm{GpC}, \mathrm{ApC}$ & Active & 25,27 \\
\hline A1 & Deaminates HBV minus-strand DNA & $\mathrm{TpC}$ & Active & $19,21,25$ \\
\hline A2 & NI & NI & Not active & 25 \\
\hline $\mathrm{A} 3 \mathrm{~A}$ & Deaminates each strand of HBV DNA & Weak bias & Active/not active ${ }^{a}$ & $4,17,25$ \\
\hline A3B & Deaminates each strand of HBV DNA & $\mathrm{GpC}, \mathrm{ApC}$ & Active & $4,16,24-26,28,37$ \\
\hline $\mathrm{A} 3 \mathrm{C}$ & Deaminates HBV minus-strand DNA & No bias & Active but weak/not active ${ }^{a}$ & $16-18,20,26,37$ \\
\hline $\mathrm{A} 3 \mathrm{DE}$ & Not active & N/A & NI & 17 \\
\hline $\mathrm{A} 3 \mathrm{~F}$ & Deaminates each strand of HBV DNA & $\mathrm{TpC}, \mathrm{GpC}$ & Active & $16-18,20,25,26,37$ \\
\hline $\mathrm{A} 3 \mathrm{G}$ & Deaminates each strand of HBV DNA & $\mathrm{CpC}$ & Active & $16-18,20,26,37,75$ \\
\hline $\mathrm{A} 3 \mathrm{H}$ & Deaminates each strand of HBV DNA & $\mathrm{TpC}$ & NI & 17,20 \\
\hline
\end{tabular}

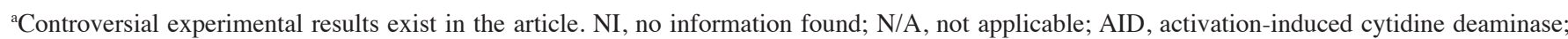
APOBEC, apolipoprotein B mRNA editing enzyme, catalytic polypeptide-like; HBV, hepatitis B virus.

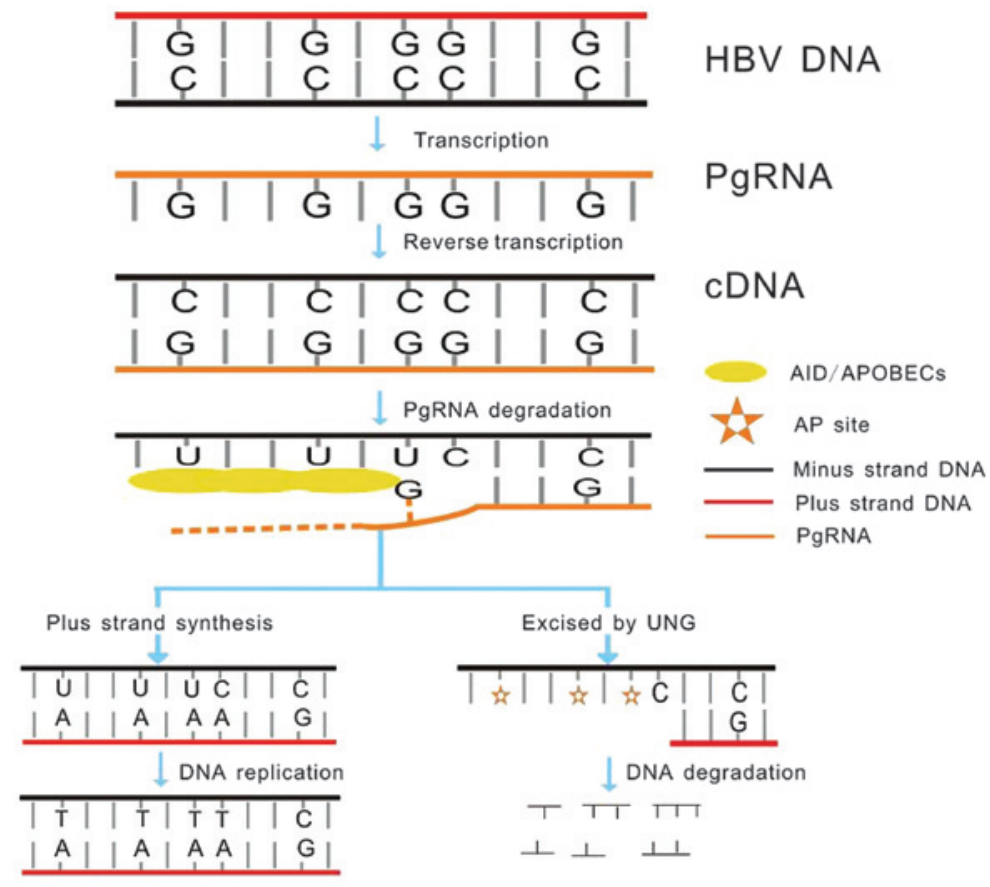

Figure 1. HBV DNA is transcribed to pgRNA as a replicative RNA intermediate, according to which the minus DNA strand (cDNA) forms. ssDNA is formed as the pgRNA is degraded. AID/APOBECs catalyze cytosine deamination of HBV DNA on the cDNA, producing uracil during reverse transcription. Uracils in DNA (including cccDNA) are recognized and excised by UNG leading to formation of AP sites. These AP sites are recognized by cellular AP endonucleases leading to DNA digestion. The HBV DNAs that do not undergo degradation, generate C-to-T transitions in minus strand DNA and G-to-A transitions in plus strand DNA during general DNA replication. HBV, hepatitis B virus; pgRNA, pregenomic RNA; ssDNA, single stranded DNA; AID, activation-induced cytidine deaminase; APOBEC, apolipoprotein B mRNA editing enzyme, catalytic polypeptide-like; cccDNA, covalently closed circular DNA; UNG, uracil DNA glycosylases; AP, apurinic/apyrimidinic.

expression may contribute to the antiviral effects of IFN- $\alpha$ against HBV DNA. In addition to IFN- $\alpha$, other IFN family members, such as IFN- $\gamma$ and IFN- $\beta$, directly upregulate $\mathrm{A} 3 \mathrm{G}$ expression in macrophages $(39,41)$. IFN- $\gamma$ is known to control HBV in a dose-dependent reduction manner, which was consistent with the observation of a dose-dependent increase in A3G and $\mathrm{A} 3 \mathrm{~F}$ protein expression following IFN- $\gamma$ therapy (42). In addition, the expression of AID is induced in response to tumor necrosis factor (TNF)- $\alpha$. Interleukin (IL)-1 $\beta$ stimulation in cultured human hepatocytes and pro-inflammatory cytokine-mediated expression was meditated by nuclear factor- $\kappa \mathrm{B}$ signaling pathways $(43,44)$ and by IL-4 and -13 through STAT6 $(45)$. Transforming growth factor- $\beta$ is a cytokine that induces AID in B and HepG 2 cells (46), whereas TNF- $\alpha$ and IL-1 $\beta$ stimulate the expression of A2 in human hepatocytes (44).

\section{Specific regulation of editing by AID/APOBECs}

Mechanism of regulation. The mutagenic activity resulting from AID/APOBEC-mediated deamination is toxic for 
retroviruses and beneficial to organisms in host cell defense (13). However, its excessive activity and off-target mutations within the cellular genome are also toxic and oncogenic to the host. Thus, organisms possess multiple mechanisms to regulate the expression of AID/APOBECs; for example, controlling their enzymatic activity and restricting their access to DNA or RNA substrates (47). A1 is the sole family member capable of recognizing and using mRNA as a substrate. Editing only occurs on cytidines $5^{\prime}$ of the mooring sequence (48). Although RNA editing occurs in the cytoplasm when A1 is overexpressed (49), cytoplasmic A1 editing activity is suppressed under normal physiological conditions. In addition, RNA editing is restricted to the cell nucleus within a temporal and spatial window that occurs subsequent to pre-mRNA splicing and prior to mRNA nuclear export, only when interacting with cofactor, APOBEC-1 complementation factor $(50,51)$. The sequence requirements for AID/APOBEC deamination are not stringent, however, deamination generally occurs within transcribed or single-stranded regions of DNA. Therefore, single-stranded (ss)DNA is always recognized as a substrate by the AID/APOBEC family. The deaminase activity of AID is responsible for a variety of point mutations and DNA breaks. This mutagenic activity leads to somatic hypermutation (SHM) and class switch recombination (52). Notably, the expression of AID is restricted to activated B cells under physiological conditions, and only targets variable and switch regions of immunoglobulin genes for mutagenesis. A2 is essential for muscle development with its expression being largely restricted to striated muscle. However, in vitro $(32,53)$ A2 was identified to lack autonomous deaminase activity. The above-mentioned processes are regulated in a tissue-specific manner during development and in response to metabolic regulation. Furthermore, subcellular localization and RNA binding to AID/APOBECs regulate their deaminase activity. Furthermore, AID is regulated by nuclear-cytoplasm transport and is predominantly located in the cytoplasm. Controlling the abundance of AID exclusion from the nucleus in steady state is one of the major regulatory mechanisms restricting its contact with genomic material $(54,55)$. A $3 \mathrm{G}$ is strongly retained in the cytoplasm and excluded from chromosomes based on the specialized property of a novel cytoplasmic retention signal (56). A3G is present in two distinct molecular forms within the cell: A low molecular mass form and a high molecular mass (HMM) complex, which contains one or more inhibitory RNAs that inactivate ssDNA deaminase activity (57-59). A3G-RNA complexes in viral particles have been found to be inactive until RNase $\mathrm{H}$ activity of reverse transcriptase (RT) degrades the RNA of DNA-RNA hybrids (60). A3C, A3F and A3H all form intracellular HMM complexes (61-63) in addition to A3G. AID exerts no measurable deaminase activity on ssDNA unless the AID is pretreated with RNase to remove the inhibitory RNA, which is bound to the AID (29).

\section{Role of AID/APOBECs in HBV-associated disease pro- gression}

Promotion of the evolution of $H B V$ virus. The encapsidated HBV genome consists of a 3.2-kb partially double-stranded relaxed circular (rc)DNA molecule. Upon translocation to the nucleus, the rcDNA genome is converted into a cccDNA by cellular repair factors and remains an episomal minichromosome, which transcribes all viral RNAs, including pregenomic (pg)RNA as a replicative RNA intermediate. The pgRNA is translated to form the core protein and internal translation initiation synthesizes the DNA polymerase. The pgRNA, viral core, and polymerase proteins are assembled into the nucleocapsid in the cytoplasm (1). Reverse transcription starts to synthesize the (minus) DNA strand via reverse transcription activity of the viral polymerase. Following degradation of the pgRNA by the viral RNase $\mathrm{H}$, the plus strand is synthesized to form mature core particles, which interact with the preS domain of the membrane-associated viral surface proteins and acquire the viral envelope (64). Approximately $10^{11}$ viral particles are released per day into the circulation of individuals with the chronic HBV infection and HBV particles are cleared from the plasma with a half-life of $\sim 1.0$ day $(65,66)$. In the initial immunotolerant phase of chronic HBV infection, the immune pressure is weak. With the progression of chronic infection, especially during Hepatitis $\mathrm{B}$ e antigen ( $\mathrm{HBeAg}$ ) seroconversion, HBV mutations gradually occur (67). The mutation rate of HBV DNA caused by AID/APOBECs in chronic HBV infection patients has been shown to be higher than that of acute HBV infection patients. In the chronic HBV infection group, the frequency of hypermutated genomes was found to be higher in $\mathrm{HBeAg-negative} \mathrm{individuals} \mathrm{when}$ compared with seropositive cases $(68,69)$, and the degree of mutation of the HBV DNA was significantly associated with the extent of fibrosis (68). This may have been due to the fact that $\mathrm{HBeAg}$-negative patients had undergone $\mathrm{HBeAg}$ seroconversion, resulting in an already elevated immune response (70). Although mutations in A3 that result in altered editing can be highly deleterious, lightly edited genomes may facilitate the virus to evolve and even escape from the immune responses (21). Non-resolving inflammation has been shown to be indispensable for immune-selection of the AID/APOBECs-dependent HBV mutations (6).

\section{Inhibition of HBV by AID/APOBEC proteins}

A3s are effective inhibitors of $H B V D N A$ replication. A3s are effective restrictive factors for various types of virus with ssDNA, including HBV. It has been shown that A3 catalyzes cytosine deamination of HBV DNA produced during reverse transcription as a template, resulting in the presence of uracil in cDNA. Uracils in DNA (including cccDNA) are recognized and excised by cellular uracil DNA glycosylases (UNGs) leading to formation of apurinic/apyrimidinic (AP) sites, which are then recognized by cellular AP endonucleases resulting in DNA digestion (Fig. 1) (4,71-73). Certain studies describe contradictory results and report that the loss of UNG does not restore the levels of viral reverse transcripts, which had been decreased by A3G (74). A previous study found that HBV replication was inhibited by A3G (75). However, the G-to-A hypermutation was not observed in HBV DNA. Further studies using a 3D-polymerase chain reaction (PCR) method showed that A3B, A3C, A3F and A3G extensively deaminated cytidine residues in minus strand DNA. Unexpectedly, three of the four enzymes (A3B, A3F and A3G) deaminated HBV plus strand DNA in human HCC cell lines; however, the underlying mechanism remained undetermined (16). In 


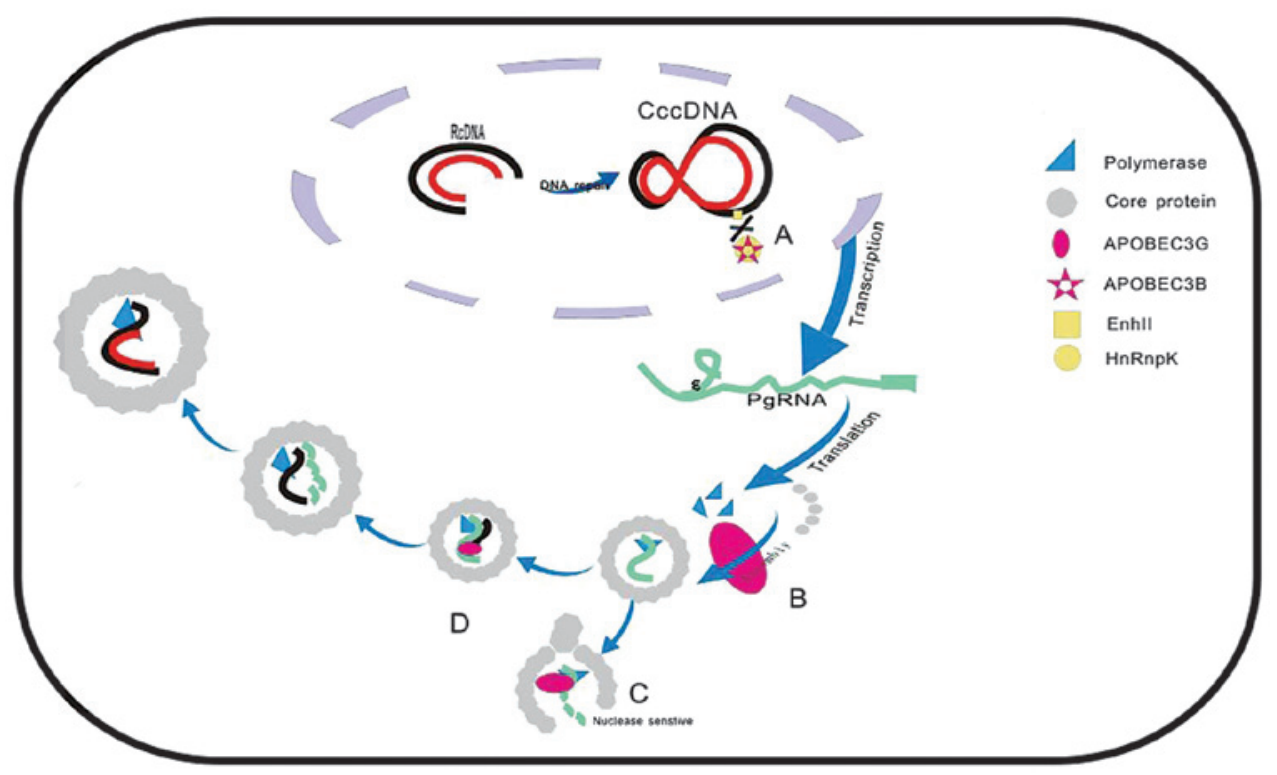

Figure 2. The rcDNA genome is converted into cccDNA by cellular repair factors. Then, the cccDNA is transcribed to the pgRNA and subgenomic mRNAs (not shown). The mRNAs are transported to the cytoplasm. The pgRNA is translated in the cytosol to form HBV core protein and the viral polymerase. These three components assemble to form the core particle. The first (minus) DNA strand forms within the core particles via reverse transcription of the pgRNA to DNA; the pgRNA is degraded by viral RNase $\mathrm{H}$ as the plus strand is synthesized. (A) A3B inhibits the binding of HnRnp K to the Enh II of HBV; (B) A3G may inhibit pgRNA packaging; (C) A3G renders HBV core protein-associated full-length pgRNA nuclease-sensitive; (D) A3G blocks DNA strand elongation and targets a DNA-RNA hybrid. rcDNA, relaxed circular DNA; cccDNA, covalently closed circular DNA; pgRNA, pregenomic RNA; HBV, hepatitis B virus; APOBEC, apolipoprotein B mRNA editing enzyme, catalytic polypeptide-like; HnRnp K, heterogeneous nuclear ribonucleoprotein K; Enh II, enhancer II.

another study, Henry et al (17) compared the HBV editing by all seven enzymes in a quail cell line, which did not produce any endogenous DNA cytidine deaminase activity. The study identified that all of the A3s, not including A3DE, deaminated the HBV DNA levels from $10^{-2}$ to $10^{-5}$ in vitro, with A3A proving to be the most efficient editor (17). The hyperediting ability of A3A was confirmed by Lucifora et al (4). Although A3C was weaker at inhibiting HBV replication compared with A3G, its capacity for DNA hyperediting was higher than A3G and $\mathrm{A} 3 \mathrm{H}(18,20)$. A3G demonstrated a strong preference for $\mathrm{CpC}$, whereas $\mathrm{A} 3 \mathrm{H}$ demonstrated a preference for $\mathrm{TpC}$ (19). These findings indicate that human A3 enzymes impact HBV replication by cytidine deamination. However, the induction of hypermutations is not sufficient for full inhibition of HBV replication.

A cytidine deaminase null mutant of A3B (E255A) was also found to inhibit HBV RNA production, although it was unable to edit HBV (28). It was proposed that only the carboxy (C)-terminal deaminase domain of A3B catalyzes HBV hypermutations $(24,26)$. By investigating a series of A3B point mutants, it was found that the $\mathrm{N}$ - and $\mathrm{C}$-terminal cytosine deaminase domains of A3B (24) and A3G (76) exerted inhibitory effects on HBV replication. By contrast, a truncated splice variant of $\mathrm{A} 3 \mathrm{~B}$ that lacked the $\mathrm{C}$-terminal deaminase domain exerted no effect on HBV replication (26). However, A3G, which was defective for deaminase activity, was found to inhibit HBV replication (75). From the above-mentioned reports, it is hypothesized that the inhibition of HBV may be mediated by additional, different mechanisms.

Possible editing-independent mechanisms. In principle, a decrease in HBV DNA may result from either accelerated DNA degradation or decreased synthesis. A previous report suggested that A3G decreased the viral DNA levels by inhibiting pgRNA packaging (75). Subsequently, Rösler et al (15) revealed that the early stages of HBV DNA morphogenesis, including RNA and protein synthesis, binding of pgRNA to the core protein, and self-assembly of the viral core protein, were unaffected. However, A3G rendered HBV core protein-associated full-length pgRNA nuclease sensitive. Nguyen et al (27) analyzed the mechanisms of deamination-independent suppression of $\mathrm{HBV}$ replication by $\mathrm{A} 3 \mathrm{G}$ and did not identify enhanced DNA degradation by $\mathrm{A} 3 \mathrm{G}$, either in vivo or in vitro. $\mathrm{A} 3 \mathrm{G}$ appeared to inhibit the very early steps in viral reverse transcription and blocked DNA strand elongation. Furthermore, the deamination-independent antiviral function of A3G targets DNA-RNA hybrids (27). The A3B protein inhibits the binding of heterogeneous nuclear ribonucleoprotein $\mathrm{K}$ to the enhancer II of HBV and represses the activity of HBV. In addition, A3B directly suppresses HBV S-promoter activity (23). The process is presented schematically in Fig. 2.

Inhibition of $H B V$ by additional APOBEC proteins. AID and A1 also inhibit HBV replication. AID was significantly upregulated in $~ 50 \%$ of HBV and HCV cirrhotic samples indicating that ectopic expression of AID was also a feature of HBV liver disease. A1 was markedly expressed in one sample (although normalization of the expression levels was not conducted), A2 transcripts were detected in certain samples, but A4 was not detected in any sample. AID was identified to be as effective as A3G at hyperediting HBV DNA (21). Mutation matrices and editing frequencies in the HBV minus strand DNA were comparable, for example, the editing frequency for A1 was $32 \%$, and for A3G was 34\% (18). C-to-T (U) hypermutations were observed in rcDNA and nucleocapsid viral RNA indicating that AID deaminates viral RNA and ssDNA (77). A1 
Table II. Summary of linkage studies between clinical indicators and AID/APOBEC.

A, APOBEC3 polymorphism studies

\begin{tabular}{|c|c|c|}
\hline Study (ref.) & Cohort description & Association with APOBEC 3 polymorphisms \\
\hline $\begin{array}{l}\text { Abe et al, } 2009 \\
\text { (85) }\end{array}$ & $\begin{array}{l}724 \text { patients with chronic HBV } \\
\text { infection and } 469 \text { healthy control } \\
\text { subjects. }\end{array}$ & $\begin{array}{l}\text { No significant association between A3B deletion polymorphism and chronic HBV carrier } \\
\text { state. A3B gene deletion homozygosity was associated with mild liver fibrosis. }\end{array}$ \\
\hline $\begin{array}{l}\text { Zhang et al, } 2013 \\
\text { (28) }\end{array}$ & $\begin{array}{l}1,124 \text { patients with } \mathrm{HBV} \text {-associated } \\
\text { HCC, } 510 \text { individuals with } \\
\text { persistent } \mathrm{HBV} \text { infection and } 826 \\
\text { healthy control subjects. } \\
\text { Population, Han Chinese. }\end{array}$ & $\begin{array}{l}\text { At least one } \mathrm{A} 3 \mathrm{~B} \text { deletion allele increased the risk for persistent } \mathrm{HBV} \text { infection and } \mathrm{HCC} \\
\text { development. }\end{array}$ \\
\hline $\begin{array}{l}\text { Ezzikouri et al, } \\
2013 \text { (86) }\end{array}$ & $\begin{array}{l}179 \text { HBV chronic carriers and } 216 \\
\text { healthy control subjects. } \\
\text { Population, Moroccan. }\end{array}$ & $\begin{array}{l}\text { No significant difference in the frequencies of deleted A3B alleles or genotypes between } \\
\text { the two groups. Patients with deleted genotypes experienced a faster progression of liver } \\
\text { disease than those with insertion genotypes. } \\
\text { A3B deletion exhibited significantly lower viral loads than patients with the wild-type. } \\
\text { A3G H186R polymorphism R/R genotype frequencies were not significantly different in } \\
\text { the HBV-infected patients and healthy subjects. }\end{array}$ \\
\hline
\end{tabular}

B, Hypermutation studies

\begin{tabular}{lll} 
Study (ref.) & \multicolumn{1}{c}{ Cohort description } & \multicolumn{1}{c}{ Association with hypermutation } \\
\hline $\begin{array}{l}\text { Beggel } \text { et al, } 2013 \\
(68)\end{array}$ & $\begin{array}{l}80 \text { treatment-naïve HBV infection } \\
\text { patients (47 HBeAg-positive } \\
\text { and 33 HBeAg-negative). }\end{array}$ & $\begin{array}{l}\text { Hypermutation rates for HBeAg-negative patients were }>10 \text {-fold higher than those of } \\
\text { HBeAg-positive patients. HBeAg-negative patients higher hypermutation rates were } \\
\text { significantly associated with the degree of fibrosis. }\end{array}$ \\
$\begin{array}{l}\text { Noguchi } \text { et al, 2005 Japanese adult patients with acute } \\
\text { (69) }\end{array}$ & $\begin{array}{l}\text { Hypermutated HBV DNA was detected in 1/8 patients with acute HBV infection and 4/10 } \\
\text { patients with chronic HBV infection. In the latter group, hypermutated genomes were } \\
\text { found only in eAb-positive patients. }\end{array}$ \\
\hline
\end{tabular}

C, APOBEC3 expression studies

\begin{tabular}{|c|c|c|}
\hline Study (ref.) & Cohort description & Association with APOBEC 3 expression \\
\hline $\begin{array}{l}\text { Vartanian et al, } \\
2010(21)\end{array}$ & $\begin{array}{l}41 \text { cirrhotic samples }(10 \text { alcoholic } \\
\text { cirrhosis, } 10 \mathrm{HBV}^{+}, 11 \mathrm{HBV}^{+} \mathrm{HCV}^{+} \\
10 \mathrm{HCV}^{+}, 4 \text { normal livers). }\end{array}$ & $\begin{array}{l}\text { 5/7 A3 genes were significantly upregulated in the order: } \mathrm{HCV} \pm \mathrm{HBV}>\mathrm{HBV}> \\
\text { alcoholic cirrhosis. A3C and A3D were up regulated for all groups. Interferon inducible } \\
\text { A3G was overexpressed in virus-associated cirrhosis, as was AID in } 50 \% \text { of these } \\
\mathrm{HBV} / \mathrm{HCV} \text { samples. }\end{array}$ \\
\hline $\begin{array}{l}\text { Xu et al, } 2007 \\
(37)\end{array}$ & $\begin{array}{l}29 \text { pairs of } \mathrm{HCC} \text { and surrounding } \\
\text { non-cancerous tissue samples. }\end{array}$ & A3B transcripts were significantly elevated in $24 / 29 \mathrm{HCC}$. \\
\hline $\begin{array}{l}\text { Kou et al, } 2007 \\
(46)\end{array}$ & $\begin{array}{l}51 \mathrm{HCC}^{\text {patients }}\left(14 \mathrm{HBV}^{+} \text {, }\right. \\
\left.30 \mathrm{HCV}^{+}\right) \text {with } 25 \mathrm{CH} \text { and } 26 \mathrm{LC} \\
\text { patients, and } 6 \text { normal livers. }\end{array}$ & $\begin{array}{l}\text { AID was significantly upregulated in } \mathrm{HCC} \text { and surrounding non-cancerous liver tissues } \\
\text { underlying } \mathrm{CH} \text { or LC. }\end{array}$ \\
\hline
\end{tabular}

AID, activation-induced cytidine deaminase; APOBEC, apolipoprotein B mRNA editing enzyme, catalytic polypeptide-like; HBV, hepatitis B virus; $\mathrm{CH}$, chronic hepatitis; LC, liver cirrhosis; HCC, hepatocellular carcinoma; HBeAg, hepatitis B e antigen.

exhibited a strong preference for $\mathrm{TpC}$ and a strong aversion to GpC (19) and AID editing of the HBV target was concentrated at the $\mathrm{GpC}$ and $\mathrm{ApC}$ sites (21). Furthermore, the low expression levels of A1 and AID in Huh7 cells was consistently associated with decreased levels of core-associated HBV DNA by quantitative PCR. However, A2 did not exert any effect on HBV replication (25).

AID/APOBECs incorporation into viral particles. Research on $\mathrm{HBV}$ reveals that the antiviral activity of $\mathrm{A} 3 \mathrm{G}$ requires incorporation into assembling viral particles to inhibit reverse transcription. Factors required for incorporation of the antiviral deaminase protein, A3G into HBV nucleocapsids continues to be investigated. It has been demonstrated that A $3 \mathrm{G}$ and $\mathrm{A} 3 \mathrm{C}$ bind to the $\mathrm{HBV}$ core protein in immunoprecipitation experiments $(78,79)$. Such binding is essential for reverse transcription following infection. The binding of $\mathrm{A} 3 \mathrm{G}$ to the HBV core protein was only indirectly demonstrated with coexpression of RT and pgRNA, however, not with core protein alone $(15,18)$. The results are consistent with the findings of Nguyen et al (80) that A3G was specifically incorporated into replication-competent $\mathrm{HBV}$ nucleocapsids by interacting with viral RT and RNA packaging signals. However, by fluorescence resonance energy transfer (FRET) and acceptor 
Table III. Summary of linkage studies between HCC and AID/APOBECs.

\begin{tabular}{|c|c|c|c|}
\hline Protein & $\begin{array}{l}\text { Experimental } \\
\text { targets }\end{array}$ & Indication & Reference \\
\hline A1 & TM, TR & All of the TM and one TR had liver dysplasia. 8/35 TM developed HCC. & 95 \\
\hline A1 & TM, TR & $\begin{array}{l}\text { The aberrant editing markedly reduced levels of protein expression by the } \\
\text { tumor suppressor gene, NAT1. }\end{array}$ & 96 \\
\hline A2 & $\mathrm{TM}$ & $\begin{array}{l}\text { HCC developed in } 2 / 20 \mathrm{~A} 2 \mathrm{TM} \text { at } 72 \text { weeks of age. Significantly high } \\
\text { frequencies of nucleotide alterations in EIF } 4 G 2 \text { and PTEN genes were } \\
\text { observed in hepatocytes. }\end{array}$ & 97 \\
\hline A3 & $\mathrm{CL}, \mathrm{HCCT}$ & $\begin{array}{l}\text { C-terminally truncated } H B x \text { mutants generated by } \mathrm{A} 3 \text { enhanced the colony } \\
\text { forming ability and proliferative capacity of neoplastic cells. A3B upregulated } \\
H S F 1 \text {. }\end{array}$ & 37 \\
\hline $\mathrm{A} 3 \mathrm{~A}$ & CL & $\begin{array}{l}\text { A3A led to induction of cellular DNA breaks and activation of damage } \\
\text { responses in a deaminase-dependent manner. A3A expression induced cell } \\
\text { cycle arrest. }\end{array}$ & 98 \\
\hline AID & CL, HCCT & $\begin{array}{l}\text { The majority of liver tissues with AID upregulation contained multiple genetic } \\
\text { changes in the p53 gene. Aberrant activation of AID in hepatocytes resulted } \\
\text { in accumulation of multiple genetic alterations in the p53 gene. }\end{array}$ & 46 \\
\hline AID & $\mathrm{TM}$ & $\begin{array}{l}\text { HCC developed in } 27 \% \text { of tissue-nonspecific alkaline phosphatase-AID TM } \\
\text { at the age of } 90 \text { weeks. The HCC expressed } \alpha \text {-fetoprotein and possessed } \\
\text { deleterious mutations in the tumor suppressor gene, TRP53. }\end{array}$ & 94 \\
\hline
\end{tabular}

photobleaching experiments, Zhao et al (81) revealed that A3G directly binds to core proteins. Similarly, direct interaction of $\mathrm{HBV}$ core protein and A3A was confirmed by proximity ligation assay and FRET analysis. Deletion analysis was used to confirm that the central region of the HBV core protein (between aa 77 and 149) was involved in the interaction with A3A (4). Additionally, the A3B, A3C and A3F enzymes were also found to be associated with the HBV capsid by interaction with the core protein (16). Similar to A3G, AID was co-immunoprecipitated with the nucleocapsid core protein. The assumption was made that AID formed a ribonucleoprotein complex with the HBV core proteins and RNA during nucleocapsid assembly in which AID deaminated cytosines of the viral RNA, including pgRNA and ssDNA (77).

\section{APOBEC polymorphisms in $\mathrm{HBV}$ infections}

The APOBEC family is considered to be significant in innate cellular immunity, particularly in HBV hyperediting and infection inhibition. It was of interest to elucidate whether gene polymorphisms alter host susceptibility to HBV progression of $\mathrm{CH}$. A3B is an efficient editor and inhibitor in the process of HBV infection. A 29.5-kb deletion between exon 5 in A3A and exon 8 in an A3B gene cluster resulted in complete removal of the $\mathrm{A} 3 \mathrm{~B}$ coding region $(82,83)$. A hybrid gene containing the coding region of $\mathrm{A} 3 \mathrm{~A}$ and the 3 '-untranslated region of $\mathrm{A} 3 \mathrm{~B}$ was initially discovered by mapping end-sequence pairs from a human fosmid library against the human genome reference sequence assembly (82). This was confirmed by dense single nucleotide polymorphism marker mapping (83). A report on the frequency of the deletion allele conducted using 1,277 diverse human samples revealed that its expression is rare in
African and European individuals (frequency of 0.9 and 6\%, respectively), more common in East Asian and Amerindian individuals (36.9 and $57.7 \%$, respectively) and almost universal in Oceanic populations (92.9\%) (84). Analyzing the association between this polymorphism and chronic HBV infection may clarify the effect of A3B on the establishment of chronic HBV carrier state. Abe et al (85) initially investigated the association between this polymorphism and chronic HBV infection. No association was identified between the chronic HBV carrier state and deletion polymorphisms; however, the extent of liver fibrosis was found to be associated with insertion homozygosity (85). Similarly, another report demonstrated that there was no significant difference in the frequencies of deleted A3B alleles or genotypes between patients with $\mathrm{CH}$ B and control subjects. By contrast, subjects bearing a deleted genotype experienced a more rapid progression of liver disease when compared with those exhibiting an insertion genotype (86). This result indicated that in the A3B deletion polymorphism, A3 cytidine deaminases do not predispose an individual to chronicity, but may modulate the course of persistent HBV infection. These results are contradictory to a study, which revealed that a $29.5-\mathrm{kb}$ deletion obliterated the production of A3B, and was significantly associated with increased susceptibility to persistent HBV infection in an ethnic Han Chinese population (28).

Seven haplotypes (designated with Roman numerals, I-VII) were reported to be present in various human populations based on the five single amino acid polymorphisms, N15 $\Delta$, R18L, G105R, K121D and E178D (87). The N15 $\Delta$ and R105G mutations may independently cause a marked decrease in $\mathrm{A} 3 \mathrm{H}$ expression. Only the haplotypes II, IV and VII were without these two mutations, and were stably expressed and 
found to efficiently inhibit HIV-1 replication (88). In addition, Wang et al (87) found that E140K, H54R, E56Q, C85S and C88S, as well as the two mutants, W115A and $\mathrm{W} 115 \mathrm{~L}$, disrupted $\mathrm{A} 3 \mathrm{H}$ expression. The A3G H186R polymorphisms in HBV-infected patients were found to be different to those of healthy Moroccan individuals, although the difference was not significant (86). The outcomes of a selection of studies are summarized in Table II. The association between AID/APOBEC polymorphisms and liver disease requires further, in-depth investigation.

\section{Emerging role of the AID/APOBEC family in the devel- opment of cancer}

The AID/APOBEC family and their associated editing patterns may be involved in oncogenesis. Recent analyses of the mutations have implicated APOBEC cytidine deaminases as significant factors in the mutagenesis of human cancer genomes $(89,90)$. Within cancer genomes, APOBEC mutagenesis has been found to be pervasive and correlated with APOBEC mRNA levels (89-91). Roberts et al (89) identified that tumor samples, from 14 types of cancer, contained hundreds of APOBEC-signature mutations, constituting $\leq 68 \%$ of mutations in the exome. In at least six distinct types of cancer, similar results have revealed that $\mathrm{A} 3 \mathrm{~B}$ is upregulated, and its preferred target sequence was frequently mutated and clustered (91).

AID is critical in class-switch recombination and SHM of the immunoglobulin gene in B lymphocytes (92). Animal models have demonstrated that the aberrant expression of AID contributes to HCC tumorigenesis $(93,94)$. A positive correlation between somatic mutation frequencies and AID expression levels was observed in the p53 gene in liver tissues with AID upregulation, as downregulation and somatic mutations in the p53 gene have been well characterized in human hepatocarcinogenesis (46). These data indicate that AID/APOBEC-catalyzed deamination may be important in generating somatic mutations during the progression of virus-associated HCC.

Transgenic overexpression of A1 in rabbit and mouse livers resulted in liver dysplasia and HCC through excessive editing of hepatic mRNAs, such as tyrosine kinase (95). Furthermore, hyperediting of the novel A1 target no 1 mRNA that encoded a tumor suppressor gene, created stop codons and truncated protein products, which are linked to liver cancer (96). Aberrant A2 expression resulted in nucleotide alterations in the transcripts of a specific target gene and may be involved in the development of human HCC via hepatic inflammation (97). A3 deaminases generate C-terminally truncated $H B x$ mutants, which enhance the colony-forming ability and proliferative capacity of neoplastic cells. Notably, A3B was observed to be widely upregulated in HCC tissues, and promoted the growth of neoplastic human HepG2 liver cells and upregulated heat shock transcription factor 1 expression levels (37). The expression of A3A may lead to induction of DNA breaks and activation of damage responses in a deaminase-dependent manner. Consistent with the above-mentioned observations, A3A expression was found to affect genomic integrity by inducing cell-cycle arrest (98). The outcomes of a selection of studies are summarized in Table III.

\section{Conclusion}

Innate immunity mechanisms are the first line of defense against invading viruses. The AID/APOBEC family of cytidine deaminases is significant in the regulation of tissue development, responding to metabolic regulation and facilitating innate immunity by restricting numerous types of virus, including $\mathrm{HBV}$. Unresolved issues are the mechanisms of AID/APOBEC-dependent specific recognition of HBV DNA, degradation of cccDNA, and the security and availability of experimental models, which are required for further investigation. Recent analyses of the mutations have indicated that AID/APOBEC cytidine deaminases are significant factors in the mutagenesis of human cancer genomes. A3B, which is only localized to the nucleus, is proposed to be responsible for a large proportion of dispersed and clustered mutations in multiple distinct cancers, including HCC. It is essential to elucidate the mutational processes underlying the development of cancer, and its potential implications on cancer etiology, prevention and therapy.

\section{References}

1. Gerlich WH: Medical virology of hepatitis B: How it began and where we are now. Virol J 10: 239, 2013.

2. Zoulim F: Hepatitis B virus resistance to antiviral drugs: Where are we going? Liver Int 31 (Suppl 1): 111-116, 2011.

3. Wursthorn K, Lutgehetmann M, Dandri M, Volz T, Buggisch P, Zollner B, Longerich T, Schirmacher P, Metzler F, Zankel M, et al: Peginterferon alpha-2b plus adefovir induce strong cccDNA decline and HBsAg reduction in patients with chronic hepatitis B. Hepatology 44: 675-684, 2006.

4. Lucifora J, Xia Y, Reisinger F, Zhang K, Stadler D, Cheng X, Sprinzl MF, Koppensteiner H, Makowska Z, Volz T, et al: Specific and nonhepatotoxic degradation of nuclear hepatitis B virus cccDNA. Science 343: 1221-1228, 2014

5. Wedekind JE, Dance GS, Sowden MP and Smith HC: Messenger RNA editing in mammals: New members of the APOBEC family seeking roles in the family business. Trends Genet 19: 207-216, 2003.

6. Deng Y, Du Y, Zhang Q, Han X and Cao G: Human cytidine deaminases facilitate hepatitis B virus evolution and link inflammation and hepatocellular carcinoma. Cancer Lett 343: 161-171, 2014.

7. Dickerson SK, Market E, Besmer E and Papavasiliou FN: AID mediates hypermutation by deaminating single stranded DNA. J Exp Med 197: 1291-1296, 2003.

8. Rogozin IB, Basu MK, Jordan IK, Pavlov YI and Koonin EV: APOBEC4, a new member of the AID/APOBEC family of polynucleotide (deoxy) cytidine deaminases predicted by computational analysis. Cell Cycle 4: 1281-1285, 2005.

9. Liao W, Hong SH, Chan BH, Rudolph FB, Clark SC and Chan L: APOBEC-2, a cardiac- and skeletal muscle-specific member of the cytidine deaminase supergene family. Biochem Biophys Res Commun 260: 398-404, 1999.

10. Teng B, Burant CF and Davidson NO: Molecular cloning of an apolipoprotein B messenger RNA editing protein. Science 260: 1816-1819, 1993.

11. Jarmuz A, Chester A, Bayliss J, Gisbourne J, Dunham I, Scott J and Navaratnam N: An anthropoid-specific locus of orphan C to U RNA-editing enzymes on chromosome 22. Genomics 79: 285-296, 2002.

12. Conticello SG, Thomas CJ, Petersen-Mahrt SK and Neuberger MS: Evolution of the AID/APOBEC family of polynucleotide (deoxy) cytidine deaminases. Mol Biol Evol 22: 367-377, 2005.

13. Vieira VC and Soares MA: The role of cytidine deaminases on innate immune responses against human viral infections. Biomed Res Int 2013: 683095, 2013.

14. Severi F, Chicca A and Conticello SG: Analysis of reptilian APOBEC1 suggests that RNA editing may not be its ancestral function. Mol Biol Evol 28: 1125-1129, 2011. 
15. Rösler C, Köck J, Kann M, Malim MH, Blum HE, Baumert TF and von Weizsäcker F: APOBEC-mediated interference with hepadnavirus production. Hepatology 42: 301-309, 2005.

16. Suspène R, Guétard D, Henry M, Sommer P, Wain-Hobson S and Vartanian JP: Extensive editing of both hepatitis B virus DNA strands by APOBEC3 cytidine deaminases in vitro and in vivo. Proc Natl Acad Sci USA 102: 8321-8326, 2005.

17. Henry M, Guétard D, Suspène R, Rusniok C, Wain-Hobson S and Vartanian JP: Genetic editing of HBV DNA by monodomain human APOBEC 3 cytidine deaminases and the recombinant nature of APOBEC3 G. PLoS One 4: e4277, 2009.

18. Baumert TF, Rösler C, Malim MH and von Weizsäcker F: Hepatitis B virus DNA is subject to extensive editing by the human deaminase APOBEC3C. Hepatology 46: 682-689, 2007.

19. Gonzalez MC, Suspène R, Henry M, Guétard D, Wain-Hobson S and Vartanian JP: Human APOBEC1 cytidine deaminase edits HBV DNA. Retrovirology 6: 96, 2009.

20. Köck J and Blum HE: Hypermutation of hepatitis B virus genomes by APOBEC $3 \mathrm{G}$, APOBEC 3C and APOBEC3H. J Gen Virol 89: 1184-1191, 2008.

21. Vartanian JP, Henry M, Marchio A, Suspène R, Aynaud MM, Guétard D, Cervantes-Gonzalez M, Battiston C, Mazzaferro V, Pineau $\mathrm{P}$, et al: Massive APOBEC3 editing of hepatitis B viral DNA in cirrhosis. PLoS Pathog 6: e1000928, 2010.

22. Li D, Liu J, Kang F, Guan W, Gao X, Wang Y and Sun D: Core-APOBEC $3 \mathrm{C}$ chimerical protein inhibits hepatitis B virus replication. J Biochem 150: 371-374, 2011

23. Zhang W, Zhang X, Tian C, Wang T, Sarkis PT, Fang Y, Zheng S, $\mathrm{Yu} \mathrm{XF}$ and $\mathrm{Xu} \mathrm{R}$ : Cytidine deaminase APOBEC3B interacts with heterogeneous nuclear ribonucleoprotein $\mathrm{K}$ and suppresses hepatitis B virus expression. Cell Microbiol 10: 112-121, 2008.

24. Bonvin M and Greeve J: Effects of point mutations in the cytidine deaminase domains of APOBEC3B on replication and hypermutation of hepatitis B virus in vitro. J Gen Virol 88: 3270-3274, 2007.

25. Jost S, Turelli P, Mangeat B, Protzer U and Trono D: Induction of antiviral cytidine deaminases does not explain the inhibition of hepatitis B virus replication by interferons. J Virol 81 : 10588-10596, 2007.

26. Bonvin M, Achermann F, Greeve I, Stroka D, Keogh A Inderbitzin D, Candinas D, Sommer P, Wain-Hobson S Vartanian JP and Greeve J: Interferon-inducible expression of APOBEC 3 editing enzymes in human hepatocytes and inhibition of hepatitis B virus replication. Hepatology 43: 1364-1374, 2006.

27. Nguyen DH, Gummuluru S and Hu J: Deamination-independent inhibition of hepatitis $B$ virus reverse transcription by APOBEC3G. J Virol 81: 4465-4472, 2007.

28. Zhang T, Cai J, Chang J, Yu D, Wu C, Yan T, Zhai K, Bi X Zhao $\mathrm{H}, \mathrm{Xu} \mathrm{J}$, et al: Evidence of associations of APOBEC3B gene deletion with susceptibility to persistent HBV infection and hepatocellular carcinoma. Hum Mol Genet 22: 1262-1269, 2013.

29. Bransteitter R, Pham P, Scharff MD and Goodman MF: Activation-induced cytidine deaminase deaminates deoxycytidine on single-stranded DNA but requires the action of RNase. Proc Natl Acad Sci USA 100: 4102-4107, 2003.

30. Muramatsu M, Sankaranand VS, Anant S, Sugai M, Kinoshita K, Davidson NO and Honjo T: Specific expression of activation-induced cytidine deaminase (AID), a novel member of the RNA-editing deaminase family in germinal center B cells. J Biol Chem 274: 18470-18476, 1999.

31. Vonica A, Rosa A, Arduini BL and Brivanlou AH: APOBEC2, a selective inhibitor of TGF $\beta$ signaling, regulates left-right axis specification during early embryogenesis. Dev Biol 350: 13-23, 2011.

32. Sato Y, Probst HC, Tatsumi R, Ikeuchi Y, Neuberger MS and Rada C: Deficiency in APOBEC2 leads to a shift in muscle fiber type, diminished body mass and myopathy. J Biol Chem 285 : 7111-7118, 2010

33. Etard C, Roostalu U and Strahle U: Lack of Apobec2-related proteins causes a dystrophic muscle phenotype in zebrafish embryos. J Cell Biol 189: 527-539, 2010.

34. Koning FA, Newman EN, Kim EY, Kunstman KJ, Wolinsky SM and Malim MH: Defining APOBEC3 expression patterns in human tissues and hematopoietic cell subsets. J Virol 83: 9474-9485, 2009.

35. Tanaka Y, Marusawa H,Seno H, Matsumoto Y,Ueda Y,Kodama Y, Endo Y, Yamauchi J, Matsumoto T, Takaori-Kondo A, et al: Anti-viral protein APOBEC3G is induced by interferon-alpha stimulation in human hepatocytes. Biochem Biophys Res Commun 341: 314-319, 2006.
36. Refsland EW, Stenglein MD, Shindo K, Albin JS, Brown WL and Harris RS: Quantitative profiling of the full APOBEC3 mRNA repertoire in lymphocytes and tissues: Implications for HIV-1 restriction. Nucleic Acids Res 38: 4274-4284, 2010.

37. Xu R, Zhang X, Zhang W, Fang Y, Zheng S and Yu XF: Association of human APOBEC3 cytidine deaminases with the generation of hepatitis virus $\mathrm{B} \times$ antigen mutants and hepatocellular carcinoma. Hepatology 46: 1810-1820, 2007.

38. Stenglein MD, Burns MB, Li M, Lengyel J and Harris RS: APOBEC3 proteins mediate the clearance of foreign DNA from human cells. Nat Struct Mol Biol 17: 222-229, 2010.

39. Peng G, Lei KJ, Jin W, Greenwell-Wild T and Wahl SM: Induction of APOBEC3 family proteins, a defensive maneuver underlying interferon-induced anti-HIV-1 activity. J Exp Med 203: 41-46, 2006.

40. Wang FX, Huang J, Zhang H, Ma X and Zhang H: APOBEC3G upregulation by alpha interferon restricts human immunodeficiency virus type 1 infection in human peripheral plasmacytoid dendritic cells. J Gen Virol 89: 722-730, 2008.

41. Stopak KS, Chiu YL, Kropp J, Grant RM and Greene WC: Distinct patterns of cytokine regulation of APOBEC3G expression and activity in primary lymphocytes, macrophages and dendritic cells. J Biol Chem 282: 3539-3546, 2007.

42. Argyris EG, Acheampong E, Wang F, Huang J, Chen K, Mukhtar $\mathrm{M}$ and Zhang $\mathrm{H}$ : The interferon-induced expression of APOBEC $3 \mathrm{G}$ in human blood-brain barrier exerts a potent intrinsic immunity to block HIV-1 entry to central nervous system. Virology 367: 440-451, 2007.

43. Endo Y, Marusawa H, Kinoshita K, Morisawa T, Sakurai T, Okazaki IM, Watashi K, Shimotohno K, Honjo T and Chiba T: Expression of activation-induced cytidine deaminase in human hepatocytes via NF-kappaB signaling. Oncogene 26: 5587-5595, 2007.

44. Matsumoto T, Marusawa H, Endo Y, Ueda Y, Matsumoto Y and Chiba T: Expression of APOBEC2 is transcriptionally regulated by NF-kappaB in human hepatocytes. FEBS Lett 580: 731-735, 2006.

45. Endo Y, Marusawa H, Kou T, Nakase H, Fujii S, Fujimori T, Kinoshita K, Honjo T and Chiba T: Activation-induced cytidine deaminase links between inflammation and the development of colitis-associated colorectal cancers. Gastroenterology 135: 889-898; 898 e1-e3, 2008.

46. Kou T, Marusawa H, Kinoshita K, Endo Y, Okazaki IM, Ueda Y, Kodama Y, Haga H, Ikai I and Chiba T: Expression of activation-induced cytidine deaminase in human hepatocytes during hepatocarcinogenesis. Int J Cancer 120: 469-476, 2007.

47. Smith HC, Bennett RP, Kizilyer A, McDougall WM and Prohaska KM: Functions and regulation of the APOBEC family of proteins. Semin Cell Dev Biol 23: 258-268, 2012.

48. Backus JW, Schock D and Smith HC: Only cytidines 5' of the apolipoprotein B mRNA mooring sequence are edited. Biochim Biophys Acta 1219: 1-14, 1994

49. Yang Y, Sowden MP and Smith HC: Induction of cytidine to uridine editing on cytoplasmic apolipoprotein B mRNA by overexpressing APOBEC-1. J Biol Chem 275: 22663-22669, 2000.

50. Lau PP, Xiong WJ, Zhu HJ, Chen SH and Chan L: Apolipoprotein B mRNA editing is an intranuclear event that occurs posttranscriptionally coincident with splicing and polyadenylation. J Biol Chem 266: 20550-20554, 1991.

51. Sowden MP and Smith HC: Commitment of apolipoprotein B RNA to the splicing pathway regulates cytidine-to-uridine editing-site utilization. Biochem J 359: 697-705, 2001.

52. Papavasiliou FN and Schatz DG: Somatic hypermutation of immunoglobulin genes: Merging mechanisms for genetic diversity. Cell 109 (Suppl): S35-S44, 2002.

53. Lada AG, Krick CF, Kozmin SG, Mayorov VI, Karpova TS, Rogozin IB and Pavlov YI: Mutator effects and mutation signatures of editing deaminases produced in bacteria and yeast. Biochemistry (Mosc) 76: 131-146, 2011.

54. Stavnezer J: Complex regulation and function of activation-induced cytidine deaminase. Trends Immunol 32: 194-201, 2011.

55. Patenaude AM and Di Noia JM: The mechanisms regulating the subcellular localization of AID. Nucleus 1: 325-331, 2010.

56. Bennett RP, Presnyak V, Wedekind JE and Smith HC: Nuclear Exclusion of the HIV-1 host defense factor APOBEC3G requires a novel cytoplasmic retention signal and is not dependent on RNA binding. J Biol Chem 283: 7320-7327, 2008.

57. Smith HC: APOBEC3G: A double agent in defense. Trends Biochem Sci 36: 239-244, 2011. 
58. Chiu YL, Soros VB, Kreisberg JF, Stopak K, Yonemoto W and Greene WC: Cellular APOBEC3G restricts HIV-1 infection in resting CD4+ T cells. Nature 435: 108-114, 2005.

59. McDougall WM and Smith HC: Direct evidence that RNA inhibits APOBEC3G ssDNA cytidine deaminase activity. Biochem Biophys Res Commun 412: 612-617, 2011.

60. Soros VB, Yonemoto W and Greene WC: Newly synthesized APOBEC 3G is incorporated into HIV virions, inhibited by HIV RNA and subsequently activated by RNase H. PLoS Pathog 3: e15, 2007.

61. Wang X, Dolan PT, Dang Y and Zheng YH: Biochemical differentiation of APOBEC3F and APOBEC3G proteins associated with HIV-1 life cycle. J Biol Chem 282: 1585-1594, 2007.

62. Niewiadomska AM, Tian C, Tan L, Wang T, Sarkis PT and Yu XF: Differential inhibition of long interspersed element 1 by APOBEC3 does not correlate with high-molecular-mass-complex formation or P-body association. J Virol 81: 9577-9583, 2007.

63. Tan L, Sarkis PT, Wang T, Tian C and Yu XF: Sole copy of Z2-type human cytidine deaminase APOBEC 3H has inhibitory activity against retrotransposons and HIV-1. FASEB J 23 279-287, 2009.

64. Gerelsaikhan T, Tavis JE and Bruss V: Hepatitis B virus nucleocapsid envelopment does not occur without genomic DNA synthesis. J Virol 70: 4269-4274, 1996.

65. Lewin SR, Ribeiro RM, Walters T, Lau GK, Bowden S, Locarnini S and Perelson AS: Analysis of hepatitis B viral load decline under potent therapy: Complex decay profiles observed. Hepatology 34: 1012-1020, 2001.

66. Nowak MA, Bonhoeffer S, Hill AM, Boehme R, Thomas HC and McDade H: Viral dynamics in hepatitis B virus infection. Proc Natl Acad Sci USA 93: 4398-4402, 1996.

67. Tran A, Kremsdorf D, Capel F, Housset C, Dauguet C, Petit MA and Brechot $\mathrm{C}$ : Emergence of and takeover by hepatitis $\mathrm{B}$ virus (HBV) with rearrangements in the pre-S/S and pre-C/C genes during chronic HBV infection. J Virol 65: 3566-3574, 1991.

68. Beggel B, Münk C, Däumer M, Hauck K, Häussinger D, Lengauer T and Erhardt A: Full genome ultra-deep pyrosequencing associates G-to-A hypermutation of the hepatitis B virus genome with the natural progression of hepatitis B. J Viral Hepat 20: 882-889, 2013.

69. Noguchi C, Ishino H, Tsuge M, Fujimoto Y, Imamura M, Takahashi S and Chayama K: G to A hypermutation of hepatitis B virus. Hepatology 41: 626-633, 2005.

70. Hannoun C, Horal $\mathrm{P}$ and Lindh M: Long-term mutation rates in the hepatitis B virus genome. J Gen Virol 81: 75-83, 2000.

71. Mangeat B, Turelli P, Caron G, Friedli M, Perrin L and Trono D: Broad antiretroviral defence by human APOBEC $3 \mathrm{G}$ through lethal editing of nascent reverse transcripts. Nature 424: 99-103, 2003.

72. Harris RS, Bishop KN, Sheehy AM, Craig HM, Petersen-Mahrt SK, Watt IN, Neuberger MS and Malim MH: DNA deamination mediates innate immunity to retroviral infection. Cell 113: 803-809, 2003.

73. Schrofelbauer B, Yu Q, Zeitlin SG and Landau NR: Human immunodeficiency virus type $1 \mathrm{Vpr}$ induces the degradation of the UNG and SMUG uracil-DNA glycosylases. J Virol 79: 10978-10987, 2005

74. Kaiser SM and Emerman M: Uracil DNA glycosylase is dispensable for human immunodeficiency virus type 1 replication and does not contribute to the antiviral effects of the cytidine deaminase Apobec3G. J Virol 80: 875-882, 2006.

75. Turelli P, Mangeat B, Jost S, Vianin S and Trono D: Inhibition of hepatitis B virus replication by APOBEC3G. Science 303: 1829, 2004.

76. Lei YC, Tian YJ, Ding HH, Wang BJ, Yang Y, Hao YH, Zhao XP, Lu MJ, Gong FL and Yang DL: N-terminal and C-terminal cytosine deaminase domain of APOBEC3G inhibit hepatitis B virus replication. World J Gastroenterol 12: 7488-7496, 2006

77. Liang G, Kitamura K, Wang Z, Liu G, Chowdhury S, Fu W, Koura M, Wakae K, Honjo T and Muramatsu M: RNA editing of hepatitis B virus transcripts by activation-induced cytidine deaminase. Proc Natl Acad Sci USA 110: 2246-2251, 2013.

78. Nassal M: The arginine-rich domain of the hepatitis B virus core protein is required for pregenome encapsidation and productive viral positive-strand DNA synthesis but not for virus assembly. J Virol 66: 4107-4116, 1992.
79. Schlicht HJ, Bartenschlager R and Schaller H: The duck hepatitis $\mathrm{B}$ virus core protein contains a highly phosphorylated $\mathrm{C}$ terminus that is essential for replication but not for RNA packaging. J Virol 63: 2995-3000, 1989.

80. Nguyen DH and Hu J: Reverse transcriptase- and RNA packaging signal-dependent incorporation of APOBEC $3 \mathrm{G}$ into hepatitis B virus nucleocapsids. J Virol 82: 6852-6861, 2008.

81. Zhao D, Wang X, Lou G, Peng G, Li J, Zhu H, Chen F, Li S, Liu D, Chen $\mathrm{Z}$ and Yang Z: APOBEC3G directly binds Hepatitis B virus core protein in cell and cell free systems. Virus Res 151: 213-219, 2010.

82. Tuzun E, Sharp AJ, Bailey JA, Kaul R, Morrison VA, Pertz LM, Haugen E, Hayden H, Albertson D, Pinkel D, et al: Fine-scale structural variation of the human genome. Nat Genet 37: 727-732, 2005.

83. McCarroll SA, Hadnott TN, Perry GH, Sabeti PC, Zody MC, Barrett JC, Dallaire S, Gabriel SB, Lee C, Daly MJ, et al: Common deletion polymorphisms in the human genome. Nat Genet 38: 86-92, 2006.

84. Kidd JM, Newman TL, Tuzun E, Kaul R and Eichler EE: Population stratification of a common APOBEC gene deletion polymorphism. PLoS Genet 3: e63, 2007.

85. Abe H, Ochi H, Maekawa T, Hatakeyama T, Tsuge M, Kitamura S, Kimura T, Miki D, Mitsui F, Hiraga N, et al: Effects of structural variations of APOBEC 3A and APOBEC 3B genes in chronic hepatitis B virus infection. Hepatol Res 39: 1159-1168, 2009.

86. Ezzikouri S, Kitab B, Rebbani K, Marchio A, Wain-Hobson S, Dejean A, Vartanian JP, Pineau P and Benjelloun S: Polymorphic APOBEC 3 modulates chronic hepatitis B in Moroccan population. J Viral Hepat 20: 678-686, 2013.

87. Wang X, Abudu A, Son S, Dang Y, Venta PJ and Zheng YH: Analysis of human APOBEC $3 \mathrm{H}$ haplotypes and anti-human immunodeficiency virus type 1 activity. J Virol 85: 3142-3152, 2011.

88. Harari A, Ooms M, Mulder LC and Simon V: Polymorphisms and splice variants influence the antiretroviral activity of human APOBEC3H. J Virol 83: 295-303, 2009.

89. Roberts SA, Lawrence MS, Klimczak LJ, Grimm SA, Fargo D, Stojanov P, Kiezun A, Kryukov GV, Carter SL, Saksena G, et al: An APOBEC cytidine deaminase mutagenesis pattern is widespread in human cancers. Nat Genet 45: 970-976, 2013.

90. Alexandrov LB, Nik-Zainal S, Wedge DC, Aparicio SA, Behjati S, Biankin AV, Bignell GR, Bolli N, Borg A, Børresen-Dale AL, et al: Signatures of mutational processes in human cancer. Nature 500: 415-421, 2013.

91. Burns MB, Temiz NA and Harris RS: Evidence for APOBEC3B mutagenesis in multiple human cancers. Nat Genet 45: 977-983, 2013.

92. Pasqualucci L, Bhagat G, Jankovic M, Compagno M, Smith P, Muramatsu M, Honjo T, Morse HC III, Nussenzweig MC and Dalla-Favera R: AID is required for germinal center-derived lymphomagenesis. Nat Genet 40: 108-112, 2008.

93. Chiba T and Marusawa $\mathrm{H}$ : A novel mechanism for inflammation-associated carcinogenesis; an important role of activation-induced cytidine deaminase (AID) in mutation induction. J Mol Med (Berl) 87: 1023-1027, 2009.

94. Takai A, Toyoshima T, Uemura M, Kitawaki Y, Marusawa H, Hiai H, Yamada S, Okazaki IM, Honjo T, Chiba T and Kinoshita K: A novel mouse model of hepatocarcinogenesis triggered by AID causing deleterious p53 mutations. Oncogene 28: 469-478, 2009.

95. Yamanaka S, Balestra ME, Ferrell LD, Fan J, Arnold KS, Taylor S, Taylor JM and Innerarity TL: Apolipoprotein B mRNA-editing protein induces hepatocellular carcinoma and dysplasia in transgenic animals. Proc Natl Acad Sci USA 92: 8483-8487, 1995

96. Yamanaka S, Poksay KS, Arnold KS and Innerarity TL: A novel translational repressor mRNA is edited extensively in livers containing tumors caused by the transgene expression of the apoB mRNA-editing enzyme. Genes Dev 11: 321-333, 1997.

97. Okuyama S, Marusawa H, Matsumoto T, Ueda Y, Matsumoto Y, Endo Y, Takai A and Chiba T: Excessive activity of apolipoprotein B mRNA editing enzyme catalytic polypeptide 2 (APOBEC2) contributes to liver and lung tumorigenesis. Int J Cancer 130: 1294-1301, 2012

98. Landry S, Narvaiza I, Linfesty DC and Weitzman MD: APOBEC3A can activate the DNA damage response and cause cell-cycle arrest. EMBO Rep 12: 444-450, 2011. 